\title{
High resolution measurements of carbon monoxide along a late Holocene Greenland ice core: evidence for in situ production
}

\author{
X. Fä̈n ${ }^{1}$, J. Chappellaz ${ }^{1}$, R. H. Rhodes ${ }^{2}$, C. Stowasser ${ }^{3}$, T. Blunier ${ }^{3}$, J. R. McConnell ${ }^{4}$, E. J. Brook ${ }^{1}$, S. Preunkert ${ }^{1}$, \\ M. Legrand ${ }^{1}$, T. Debois ${ }^{5}$, and D. Romanini ${ }^{5}$ \\ ${ }^{1}$ Univ. Grenoble Alpes, CNRS - UMR5183, Laboratoire de Glaciologie et Géophysique de l'Environnement (LGGE), \\ Grenoble, France \\ ${ }^{2}$ College of Earth, Ocean and Atmospheric Sciences, Oregon State University, Corvallis, OR, USA \\ ${ }^{3}$ Center for Ice and Climate, Niels Bohr Institute, University of Copenhagen, Copenhagen, Denmark \\ ${ }^{4}$ Division of Hydrologic Sciences, Desert Research Institute, Reno, NV, USA \\ ${ }^{5}$ Univ. Grenoble Alpes, CNRS - UMR5588, Laboratoire Interdisciplinaire de Physique (LIPhy), Grenoble, France \\ Correspondence to: X. Faïn (xavier.fain@lgge.obs.ujf-grenoble.fr)
}

Received: 27 April 2013 - Published in Clim. Past Discuss.: 27 May 2013

Revised: 25 February 2014 - Accepted: 9 March 2014 - Published: 22 May 2014

\begin{abstract}
We present high-resolution measurements of carbon monoxide (CO) concentrations from a shallow ice core of the North Greenland Eemian Ice Drilling project (NEEM2011-S1). An optical-feedback cavity-enhanced absorption spectrometer (OF-CEAS) coupled to a continuous melter system performed continuous, online analysis during a fourweek measurement campaign. This analytical setup generated stable measurements of $\mathrm{CO}$ concentrations with an external precision of $7.8 \mathrm{ppbv}(1 \sigma)$, based on repeated analyses of equivalent ice core sections. However, this first application of this measurement technique suffered from a poorly constrained procedural blank of $48 \pm 25 \mathrm{ppbv}$ and poor accuracy because an absolute calibration was not possible. The NEEM-2011-S1 CO record spans $1800 \mathrm{yr}$ and the long-term trends within the most recent section of this record (i.e., post $1700 \mathrm{AD}$ ) resemble the existing discrete $\mathrm{CO}$ measurements from the Eurocore ice core. However, the CO concentration is highly variable (75-1327 ppbv range) throughout the ice core with high frequency (annual scale), high amplitude spikes characterizing the record. These $\mathrm{CO}$ signals are too abrupt and rapid to reflect atmospheric variability and their prevalence largely prevents interpretation of the record in terms of atmospheric $\mathrm{CO}$ variation. The abrupt $\mathrm{CO}$ spikes are likely the result of in situ production occurring within the ice itself, although the unlikely possibility of $\mathrm{CO}$ production driven by non-photolytic, fast kinetic processes within the continuous melter system cannot be excluded. We observe
\end{abstract}

that $68 \%$ of the CO spikes are observed in ice layers enriched with pyrogenic aerosols. Such aerosols, originating from boreal biomass burning emissions, contain organic compounds, which may be oxidized or photodissociated to produce $\mathrm{CO}$ within the ice. However, the NEEM-2011-S1 record displays an increase of $\sim 0.05 \mathrm{ppbv} \mathrm{yr}^{-1}$ in baseline $\mathrm{CO}$ level prior to $1700 \mathrm{AD}(129 \mathrm{~m}$ depth) and the concentration remains elevated, even for ice layers depleted in dissolved organic carbon (DOC). Thus, the processes driving the likely in situ production of $\mathrm{CO}$ within the NEEM ice may involve multiple, complex chemical pathways not all related to past fire history and require further investigation.

\section{Introduction}

Carbon monoxide (CO) is a reactive trace gas, which plays a central role in interactions between climate and atmospheric chemistry. $\mathrm{CO}$ is the principal sink for the tropospheric hydroxyl radical $(\mathrm{OH})$, the most important oxidant in Earth's atmosphere. Up to $70 \%$ of the $\mathrm{OH}$ radicals react with $\mathrm{CO}$ in the modern troposphere (Karlsdottir and Isaksen, 2000), thus impacting the lifetimes of numerous atmospheric constituents such as methane $\left(\mathrm{CH}_{4}\right)$, non-methane hydrocarbons (NMHCs), and hydrofluorocarbons (HCFCs). Oxidation of $\mathrm{CO}$ by $\mathrm{OH}$ in the presence of high levels of nitrogen oxides $\left(\mathrm{NO}_{\mathrm{x}}\right)$ can also result in significant production 
of tropospheric ozone (Crutzen, 1973). Since CO impacts the atmospheric budgets of greenhouse gases such as $\mathrm{CH}_{4}$ and tropospheric ozone, it has a significant indirect warming potential.

A complete understanding of the modern $\mathrm{CO}$ budget and its evolution in relation to past climate variability and recent anthropogenic influences is thus required for climatechemistry models. Improving our understanding of the sensitivity of these models requires them to be evaluated over a variety of past climatic conditions. Martinerie et al. (1995) suggested that changes in the oxidative capacity of the atmosphere (i.e., the levels of atmospheric $\mathrm{OH}$ radicals) were mainly driven by $\mathrm{CO}$ levels during pre-industrial times. However, reliable records of past atmospheric $\mathrm{CO}$ at glacialinterglacial time scales are lacking, thus introducing uncertainties in models investigating climate evolution between the last glacial period, the pre-industrial Holocene, and the modern era. Such records would help, for example, to better assess the poorly constrained balance between changes in sources and sinks driving rises of atmospheric $\mathrm{CH}_{4}$ during past glacial-interglacial transitions (e.g., Valdes et al., 2005).

The short lifetime of $\mathrm{CO}$, combined with significant variability in the spatial distribution of its sources, results in large variations of atmospheric CO levels according to latitude. The present day annual mean $\mathrm{CO}$ concentrations at Summit (Greenland) and the South Pole (Antarctica) are $\sim 120$ and $\sim 50$ ppbv respectively (http://www.esrl.noaa. gov/gmd/dv/data/). The lifetime of $\mathrm{CO}$ is estimated to be in the range of 20-40 days in the tropics and up to three months in polar areas (Duncan et al., 2007). Sources of $\mathrm{CO}$ are qualitatively known, but still poorly quantified. In situ atmospheric production by $\mathrm{CH}_{4}$ and VOCs (volatile organic compounds, including isoprene and terpenes) oxidizing represents $\sim 50 \%$ of the sources. Carbon monoxide is also directly emitted to the atmosphere by biomass burning, fossil fuel combustion, and vegetation and ocean degassing (Duncan et al., 2007). Systematic monitoring of atmospheric $\mathrm{CO}$, initiated by NOAA (National Oceanic and Atmospheric Administration) in 1988, revealed a global decrease of tropospheric CO by $\sim 0.5$ ppbv yr $^{-1}$ between 1988 and 1996 (Novelli et al., 1998).

Ancient air preserved in glacial ice and firn is thus a unique archive to reconstruct the past atmospheric $\mathrm{CO}$ record. The firn is the upper layer of an ice sheet where snow transforms into ice. A large amount of air can be sampled from the interconnected open pores. Mean ages of atmospheric gas increase with firn depth. CO has only been measured in firn air at a few Northern Hemisphere sites, including Summit, the North Greenland Ice Core Project (NGRIP), and the North Greenland Eemian drilling site (NEEM) (Petrenko et al., 2013). The three Greenland records allowed for a $60 \mathrm{yr}$ reconstruction of atmospheric $\mathrm{CO}$ and revealed a peak of $\sim 155 \mathrm{ppbv}$ during the late 1970s. Isotopic measurements of the NEEM firn air suggested this pattern was driven by a change in $\mathrm{CO}$ emissions derived from fossil fuel combustion (Wang et al., 2012).

While firn air data provide a robust reconstruction of atmospheric CO in the Northern Hemisphere since 1950, the only data sets that extend beyond this date are from the pioneering studies on ice core samples by Haan et al. (1996) and Haan and Raynaud (1998). These studies found CO increased gradually from $\sim 90 \mathrm{ppbv}$ in $1850 \mathrm{AD}$ to $110 \mathrm{ppbv}$ in $\sim 1950 \mathrm{AD}$ and that $\mathrm{CO}$ levels stabilized at $\sim 90 \mathrm{ppbv}$ from 1625 to $1850 \mathrm{AD}$. Air older than $1600 \mathrm{AD}$ (>167 m depth) exhibited higher variability and elevated $\mathrm{CO}$ levels (100$180 \mathrm{ppbv}$ ) with parallel anomalies in the $\mathrm{CO}_{2}$ record. This section of the Greenland Eurocore record is thought to reflect in situ CO production rather than an atmospheric signal. Several ice core and firn studies have also been conducted in Antarctica (Haan and Raynaud, 1998; Ferretti et al., 2005; Assonov et al., 2007; Wang et al., 2010). Wang et al. (2010) clearly demonstrated the potential of measuring $\mathrm{CO}$ in ice archives and widened our knowledge of the variability of the past biogeochemical $\mathrm{CO}$ cycle by measuring both mixing and isotopic ratios from Antarctic ice cores. They concluded that significant variations in biomass burning occurred during the last $650 \mathrm{yr}$, including a decrease of $50 \%$ in the 1600s. However, due to the short CO lifetime, such Antarctic reconstructions are partially decoupled from Northern Hemisphere atmospheric CO history, and thus reliable Greenland $\mathrm{CO}$ records are needed.

Ice core $\mathrm{CO}$ concentrations are typically determined by gas chromatography using a mercuric oxide detector (Haan et al., 1996; Haan and Raynaud, 1998) or a mass spectrometer (Wang et al., 2010) combined with wet or dry extractions of the trapped gases from discrete pieces of ice (Ferretti et al., 2005). Such protocols are time consuming and result in limited time-resolution reconstructions. Furthermore, the low resolution is not optimal for investigation of in situ production processes; a single measurement averages $\mathrm{CO}$ concentrations over a depth of typically $5 \mathrm{~cm}$, while in situ production could be restricted to thinner ice layers.

In the framework of the recent NEEM $\left(77.45^{\circ} \mathrm{N}\right.$, $\left.51.06^{\circ} \mathrm{W}\right)$ drilling project, a new technique allowing for rapid and high-resolution measurement of methane $\left(\mathrm{CH}_{4}\right)$ in ice cores was developed (Stowasser et al., 2012). Gas released from bubbles in the ice is continuously extracted and $\mathrm{CH}_{4}$ levels are detected in real time using laser spectroscopy, while the liquid phase sample is directed to the continuous flow analysis (CFA) setup for chemical analysis (Kaufmann et al., 2008; Bigler et al., 2011). This technique enabled the reconstruction of an atmospheric $\mathrm{CH}_{4}$ record of unprecedented resolution spanning the last deglaciation and glaciations back to Marine Isotope Stage $5 \mathrm{~d}$ in a single field season (i.e., 2.5 months) (Chappellaz et al., 2013).

In this study, we report the first $\mathrm{CO}$ measurements from an ice core based on the coupling of continuous extraction and laser spectrometry. $\mathrm{CO}$ was continuously measured on the $340 \mathrm{~m}$ long NEEM-2011-S1 ice core along with $\mathrm{CH}_{4}$ 
concentrations (Rhodes et al., 2013) and a suite of chemical species. The objective of this study was to reconstruct an atmospheric history for $\mathrm{CO}$ over the past $1800 \mathrm{yr}$ by taking advantage of the high resolution measurements to distinguish between depth sections impacted by in situ CO production and sections preserving the atmospheric record.

\section{Methods}

\subsection{NEEM-2011-S1 ice core drilling}

The NEEM-2011-S1 ice core described in this study was drilled in northern Greenland to a depth of $410 \mathrm{~m}$. The borehole location was $200 \mathrm{~m}$ from the main NEEM borehole $\left(77.45^{\circ} \mathrm{N}, 51.06^{\circ} \mathrm{W}\right.$; elevation: $2450 \mathrm{~m}$; mean annual temperature: $-21^{\circ} \mathrm{C}$ ). Drill fluid (Estisol 240 and Coasol) was used to reduce strain during core drilling below $80 \mathrm{~m}$ depth. Two parallel sticks were cut from the ice core for continuous analysis ( $\mathrm{M}$ and B cut, each $55 \times 3.4 \times 3.4 \mathrm{~cm}$ ).

\subsection{Detecting CO with OF-CEAS}

Gas extracted from the ice core was measured with a laser spectrometer SARA developed at Laboratoire Interdisciplinaire de Physique (LIPhy, Grenoble, France) and based on Optical Feedback-Cavity Enhanced Absorption Spectroscopy (OF-CEAS; Morville et al., 2005; Romanini et al., 2006). Briefly, the OF-CEAS analyzer used here measures $\mathrm{CO}, \mathrm{CH}_{4}$, and $\mathrm{H}_{2} \mathrm{O}$ by fitting the sample gas absorption spectrum obtained in the $2325.1-2325.5 \mathrm{~nm}$ wavelength range. During this measurement campaign the rate of OF-CEAS spectrum acquisition was $6 \mathrm{~Hz}$. This SARA instrument is specifically adapted for ice core analysis where only limited volumes of gas are available. The analyzer has a $12 \mathrm{~cm}^{3}$ cavity, which is maintained at 20 mbar to create an effective cavity volume of only $0.24 \mathrm{~cm}^{3}$ at STP. Even at the low gas flow rates from continuous ice core analysis (typically $1.5 \mathrm{sccm}$ with our CFA setup) the theoretical sample transit time in the cavity remains low $(10 \mathrm{~s})$. The CFA setup therefore introduces a significantly higher degree of signal smoothing than the SARA instrument itself (Sect. 2.4).

A $2 \mu \mathrm{m}$ filter (ZUFR1, VICI AG, Switzerland) was connected on the gas line upstream of the SARA instrument to prevent dust particles from entering the optical cavity and depositing on the high reflectivity mirrors. A stable ringdown value of $>40 \mu$ s (i.e., an optical path length of $>18 \mathrm{~km}$ ) was maintained throughout the measurement campaign.

The OF-CEAS analyzer was carefully calibrated before melting the NEEM-2011-S1 core (see Supplement). However, we identified a small $\mathrm{CO}$ contamination from the mass flow controller (MFC, 5850E, Brooks Instrument, Hatfield USA) used to regulate the standard gas flow provided to the laser spectrometer during calibration. Measurement series (10 min each) of gas standards 1 and 2 (Table 1) with a constant flow of $1.5 \mathrm{sccm}$ showed an increase of $4 \pm 1 \mathrm{ppbv}$
Table 1. CO concentrations of synthetic air standards and mean values of measurements conducted on dry gas introduced via the internal loop and via the full loop. Each value is the mean of several repeated measurements $(n=2-19)$ conducted throughout the analytical campaign, where each individual measurement has an integration time of $10 \mathrm{~min}$. The stated uncertainty is 1 standard deviation. Synthetic air standards were calibrated by the NOAA GMD (Global Monitoring Division) Carbon Cycle Group and are reported on the NOAA/WMO 2004 scale.

\begin{tabular}{llll}
\hline & $\begin{array}{c}\text { NOAA } \\
\text { certified }\end{array}$ & Internal loop & Full loop \\
\hline Standard 1 & $50.2 \pm 0.7$ & $70.0 \pm 5.9(n=9)$ & $104.3 \pm 7.9(n=19)$ \\
Standard 2 & $95.4 \pm 0.9$ & $106.0 \pm 3.5(n=2)$ & $128.8 \pm 6.1(n=4)$ \\
\hline
\end{tabular}

of $\mathrm{CO}$ when controlled by the MFC, compared to a direct connection to the cylinder regulator. This degree of contamination from the MFC should be independent of standard gas composition.

\subsection{Continuous flow analysis of the gas phase}

\subsubsection{System operation}

A detailed description of the continuous gas flow analysis method and integration of the gas system into the continuous melter system at the Desert Research Institute (DRI) for the NEEM-2011-S1 analysis is provided by Stowasser et al. (2012) and Rhodes et al. (2013). Briefly, ice core sticks were melted at a mean rate of $6 \mathrm{~cm} \mathrm{~min}^{-1}$ and the water and gas bubble mixture was pumped via a debubbler and open split into a gas extraction unit. The gas was extracted by applying a pressure gradient across a gas-permeable membrane (MicroModule $0.5 \times 1$, G591, Membrana GmbH, Germany, internal volume $5.4 \mathrm{~mL}$ ) and then dried by a Nafion (Perma Pure) dryer. After each run of $\sim 8 \mathrm{~m}$ of ice core was completed, a four-port valve underneath the melter head was switched to provide a synthetic air-water (10:90) mixture to the gas analysis system. For this purpose, an in-house deionized (DI) water supply was degassed continuously by mixing it with ultra-pure $\mathrm{N}_{2}$ and passing it through another gas permeable membrane module. Note that this configuration involving continuous flow of in-house DI water is different from the loop modes described in the following section. Melting of M-cut ice sticks proceeded from bottom to top of the core and selected B-cut sticks were analyzed as replicates.

\subsubsection{Loop modes: mixing gas standards and degassed water}

The NEEM-2011-S1 methane record reported by Rhodes et al. (2013) was corrected for a $\sim 7 \%$ loss of methane due to dissolution in the sample stream. The $\mathrm{CH}_{4}$ loss was quantified by introducing a 10/90 mixture of synthetic air and DI 


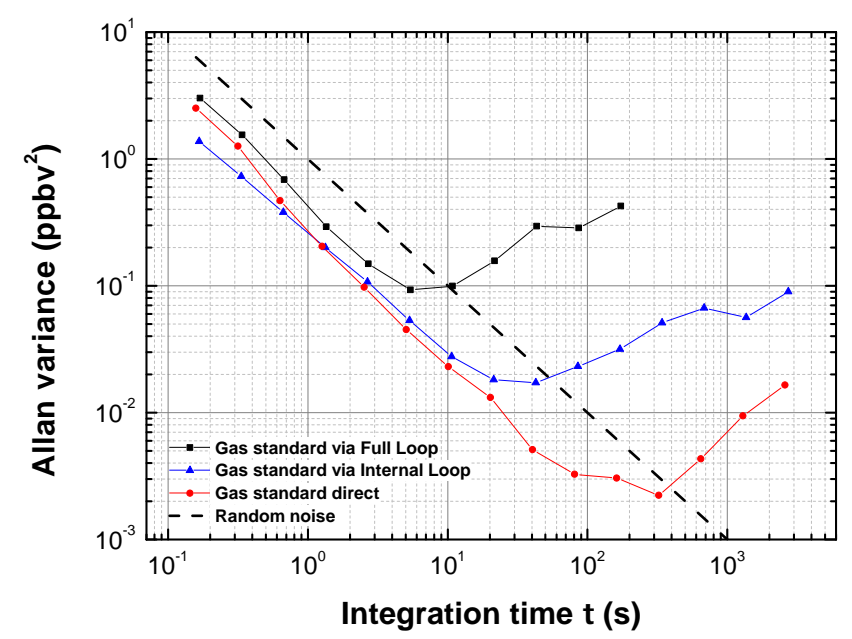

Figure 1. Allan variance results for direct gas-standard analyses conducted directly and for standard gas introduced via both the internal and the full loops.

degassed water (from an $\mathrm{N}_{2}$-purged $2 \mathrm{~L}$ reservoir) into the system via a four-port valve directly after the melter head (see Fig. 1 in Rhodes et al., 2013). The air-water mixture then followed the same path through the system as the ice core sample before being analyzed by the laser spectrometer. This sample pathway was called the "full loop". Results from analysis of the full loop are presented here and used in an attempt to quantify both solubility and contamination effects on CO levels (see Sect. 2.3.4).

A second pathway for introduction of synthetic standard gas called the "internal loop" involved a 50/50 gas standard/degassed water mixture generated inside the gas extraction unit and was used to isolate the continuous flow gas setup from the remainder of the DRI melter system. The objective was to maintain a constant gas/water mixture supply to the extraction module and therefore a constant gas flow to the OF-CEAS spectrometer.

\subsubsection{Precision of $\mathrm{CO}$ analysis}

Allan variance (Allan, 1966) evaluation was conducted for direct measurements of dry gas standard, as well as measurements on gas standard mixed with DI water in both internalloop and full-loop modes (Fig. 1).

A precision of $0.05 \mathrm{ppbv}$ is reached at the optimal integration time of 6 min when dry gas is measured directly. Optimal integration time for measurements made in the internal- and full-loop modes are 44 and $5 \mathrm{~s}$ respectively, with corresponding precisions of 0.13 and $0.30 \mathrm{ppbv}$. Allan variance analysis therefore shows that the OF-CEAS analyzer is very stable and that the continuous melting and gas extraction systems introduce drift and noise to the measurement. The achievable precision is very satisfactory for our study.

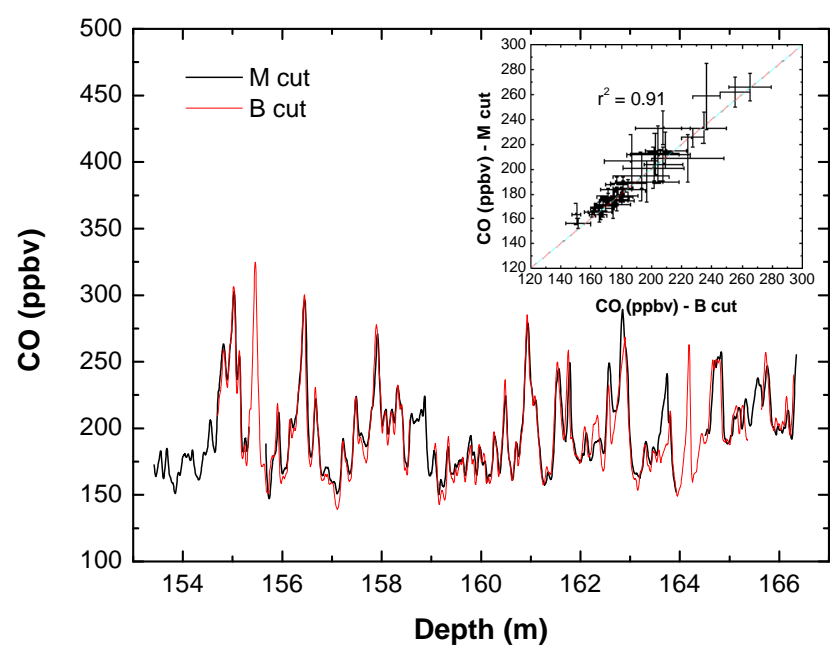

Figure 2. Replicate measurements of CO concentrations ( $M$ cut in black, B cut in red) between depths of 154-167 m. Data have not been blank corrected. Inset displays CO concentrations from cut M versus cut $\mathrm{B}$, after averaging data over $9 \mathrm{~cm}$-long depth intervals. Note that the B-cut depth scale has been slightly adjusted (i.e., a $5 \mathrm{~cm}$ offset was applied) to perfectly line up both records.

We observed relatively good reproducibility in the internal and full loop throughout the analytical campaign e.g., $8.4 \%$ relative standard deviation (RSD) for the internal loop $(n=9)$. However, both the internal- and full-loop measurements are consistently higher than the NOAA-certified $\mathrm{CO}$ concentrations (Table 1). For the internal loop an excess of 10-20 ppbv CO was recorded and this increased to 35-55 ppbv for the full loop, without accounting for a possible decrease in $\mathrm{CO}$ concentrations due to dissolution. We conclude that $\mathrm{CO}$ contamination occurs within our analytical setup and that both the gas extraction system and the wider continuous melter system contribute to this contamination.

External precision of the continuous $\mathrm{CO}$ measurements (i.e., including all sources of errors or bias) was investigated by melting replicate ice sticks on different days during the analytical campaign. Thirty-three $0.55 \mathrm{~m}$-long ice sticks from the B cut were melted for that purpose. Direct comparison of $\mathrm{CO}$ records from these B-cut sticks with data collected along the $\mathrm{M}$ cut revealed an excellent repeatability of our measurements, at least for $\mathrm{CO}$ concentrations ranging between 120 and 600 ppbv. Figure 2 reports a direct comparison of CO measured along $12 \mathrm{~m}$ of parallel $\mathrm{B}$ and $\mathrm{M}$ cuts, which were processed three days apart. A constant $5 \mathrm{~cm}$ offset has been applied on the B-cut depth scale used in Fig. 2. This offset is within the uncertainty range of the NEEM-2011-S1 depth scaling (see Sect. 2.4.2), and this correction is supported by the excellent agreement between $\mathrm{CO}$ data collected along both ice sticks. $\mathrm{CO}$ concentrations measured on both ice sticks were averaged by binning over $9 \mathrm{~cm}$-long intervals (Fig. 2, inset) and show excellent correlation $\left(r^{2}=0.91\right.$; $p<0.01)$ between averaged $\mathrm{CO}$ from cut $\mathrm{B}$ versus averaged 
CO from cut M. Such correlation demonstrates the good precision of our measurements.

CO concentrations over the 153-167 m-depth section of the NEEM-2011-S1 core exhibit highly variable values, which range from 120 to $320 \mathrm{ppbv}$ and exhibit rates of change of up to $14 \mathrm{ppbv} \mathrm{cm}^{-1}$. Figure 2 demonstrates that the analytical system replicates both the amplitude of the $\mathrm{CO}$ spikes and the highly dynamic nature of the signal. We calculate a standard deviation (sd) of $7.8 \mathrm{ppbv}$ from the comparison of these two runs (sd calculated on the difference of $\mathrm{CO}$ concentrations from cuts $\mathrm{M}$ and $\mathrm{B}$, over the $459 \mathrm{~cm}-$ long intervals represented on the inset of Fig. 2). This can be considered as the external precision of the analytical system and demonstrates the good precision of our measurements. Furthermore, as the two data sets presented in Fig. 2 have not been blank corrected, the excellent agreement between the replicate measurements suggests that the true $\mathrm{CO}$ blank of the analytical system is very constant.

\subsubsection{Accuracy of $\mathrm{CO}$ analysis: an attempt at absolute calibration}

In addition to suggesting the procedural blank was constant throughout our analytical campaign, the replicate ice stick measurements (see Sect. 2.3.3) also suggest that any losses of $\mathrm{CO}$ related to dissolution in the liquid phase were consistent. However, the magnitude of both the procedural blank and any solubility effect need to be quantified in order to obtain accurate continuous $\mathrm{CO}$ concentrations. We therefore explore whether the results from the full-loop mode (see Sect. 2.3.2) can be utilized to constrain the opposing effects of contamination and solubility.

For this purpose, an ideal calibration curve of dry-gas measurement ( $x$ axis) vs. full-loop measurements ( $y$ axis) would have a slope reflecting dissolution losses and an offset reflecting the degree of contamination from the system. A calibration curve constructed from the full-loop results (Table 1) would suggest a 50\% CO loss due to solubility (slope of $\sim 0.5$ ) and an offset (i.e., procedural blank) of $\sim 75$ ppbv. The continuous NEEM-2011-S1 methane record suffered $\mathrm{a} \sim 7 \%$ loss of methane due to dissolution in the sample stream with the DRI CFA setup (Rhodes et al., 2013), a value confirmed by comparison with discrete $\mathrm{CH}_{4}$ analysis. $\mathrm{CO}$ is slightly less soluble in water than $\mathrm{CH}_{4}$, and thus one would also expect limited $(<7 \%)$ dissolution of $\mathrm{CO}$ between the melter head and the gas extraction membrane.

Note that $7 \%$ is lower than the theoretical dissolution of $\sim 14 \%$, a factor expected for $\mathrm{CH}_{4}$ if equilibrium was reached between liquid and gas phases in a 90/10 mix $\left(16 \mathrm{~mL} \mathrm{~min}^{-1}\right.$ water and $1.8 \mathrm{~mL} \mathrm{~min}^{-1}$ gas). It is likely that the transfer time from the melter head to the extraction membrane is too short to reach equilibrium, and that the MicroModule membrane allows for extraction of some of the dissolved gas. We conclude that a $50 \%$ dissolution loss estimated by the standard gas data collected in the full-loop mode (Table 1) is unrealistic and cannot be used to set the CO NEEM-2011$\mathrm{S} 1$ record on an absolute concentration scale. This large estimate may alternatively suggest that $\mathrm{CO}$ adsorption occurs in the analytical system.

A more realistic estimation of the procedural blank can be obtained by conservatively combining all the full-loop data from standards 1 and 2 to calculate the difference between full-loop and NOAA-certified CO concentrations. This results in a procedural blank of $48 \pm 25$ ppbv, once contamination produced by the MFC is removed (to avoid correcting twice for this effect) (Sect. 2.2). We note that this calculation does not account for potential $\mathrm{CO}$ losses during the standard measurements. To test this result, ultra high purity (UHP) $\mathrm{N}_{2}$ was mixed with DI water and run through the full loop in September 2013, two years after the NEEM-2011-S1 analysis. Direct measurement of the UHP $\mathrm{N}_{2}$ on the OF-CEAS analyzer shows CO mixing ratios below detection limit. Gas extraction and analysis in this configuration was repeated three times, and revealed $\mathrm{CO}$ mixing ratios ranging between 40 and 50 ppbv. These tests involving UHP $\mathrm{N}_{2}$ were not carried out during the NEEM-2011-S1 campaign, and thus were not used to calibrate the data. However, they provide an estimation of the $\mathrm{CO}$ procedural blank, which agrees well with the value stated above. However, we caution that such tests should ideally be conducted with $\mathrm{CO}$-free air to observe possible effects on $\mathrm{CO}$ concentration of interactions between oxygen and the system components.

The principal shortcoming of the continuous measurement technique is the uncertainty regarding the absolute concentration and this is particularly true in the case of the highly contamination-sensitive $\mathrm{CO}$ measurement. All the $\mathrm{CO}$ data collected along the NEEM-2011-S1 core were corrected for a 48 ppbv procedural $\mathrm{CO}$ blank. As the measurements on replicate ice sticks (Sect. 2.3.3) strongly suggest a consistent procedural blank level, we suggest that the large uncertainty in our estimate of the procedural blank from fullloop data $( \pm 25 \mathrm{ppbv})$ reflects variable levels of contamination originating from additional pump, tubing, connectors, etc., which are present in the full loop but not in the sample pathway. Our CO data set has not been adjusted for potential solubility losses, which should be proportional to the concentration. Assuming that $\mathrm{CO}$ and $\mathrm{CH}_{4}$ solubility losses are similar (i.e., lower than $10 \%$ ), CO concentrations are likely to be underestimated for values well above standard 2 level (95.4 ppbv).

In summary, the continuous high-resolution $\mathrm{CO}$ record collected along the NEEM-2011-S1 ice core shows a good precision, but its accuracy and internal consistency are low. Improvement of the absolute calibration would include measuring more standard gases, including an elevated $\mathrm{CO}$ concentration standard and CO-zero air. Additionally, comparison with discrete $\mathrm{CO}$ analyses is required to confirm a CFAbased calibration. In the following, we focus on a qualitative discussion of the NEEM-2011-S1 CO record, where the precise measurements allow trends to be discussed. 


\subsection{Data processing and depth scaling}

The entire CO data set collected along the NEEM-2011-S1 core was averaged with a $5 \mathrm{~s}$ window, i.e., a duration shorter than the sample transit time in the spectrometer cavity (see Sect. 2.2). $\mathrm{CH}_{4}$ data from NEEM-2011-S1 were screened for ambient air contamination (Rhodes et al., 2013) and any time series removed from the $\mathrm{CH}_{4}$ data set was also removed from the $\mathrm{CO}$ data set. Sections of the $\mathrm{CO}$ record affected by water vapor in the cavity are not considered here.

Depth scaling of the CO data collected along the NEEM2011-S1 core was achieved by using the start/stop times recorded during melting, and by assuming a constant melt rate for each $55 \mathrm{~cm}$ core section. We estimated the time delay between the end of ice core melting at the melter head and the response of the CO signal measured by the OF-CEAS spectrometer (2.6-4.3 min range) daily. To do so, we allowed air from the cold room to enter the sampling line at the end of a melting run, which resulted in a clear, sharp methane peak measured on the OF-CEAS spectrometer. The uncertainty revealed by these estimates corresponds to a depth uncertainty of $\pm 6 \mathrm{~cm}(2 \sigma)$ (equivalent to $0.3 \mathrm{yr}$ in age).

Signal smoothing resulting from memory effects and diffusion was calculated by performing a step test, i.e., a switch between two gas standards of different concentrations, following the methods of Stowasser et al. (2012) and Gkinis et al. (2011). Both $\mathrm{CO}$ and $\mathrm{CH}_{4}$ step patterns were investigated. $\mathrm{CO}$ step analysis indicates that $5 \mathrm{~min}$ - equivalent to $30 \mathrm{~cm}$ of sample length - have to be removed from the start of each $8 \mathrm{~m}$ melting run so as to eliminate effects of sample mixing with gas standard in the system. $\mathrm{CH}_{4}$ step analysis reported previously by Rhodes et al. (2013) indicated that $7 \mathrm{~min}$ of data, equivalent to $42 \mathrm{~cm}$ sample length, had to be removed from the start of each $8 \mathrm{~m}$ melting run so as to eliminate $\mathrm{CH}_{4}$-related memory effect. $\mathrm{CO}$ and $\mathrm{CH}_{4}$ data from the NEEM-2011-S1 core were processed together, and so $7 \mathrm{~min}$ of data from both $\mathrm{CH}_{4}$ (Rhodes et al., 2013) and $\mathrm{CO}$ (this study) were conservatively discarded from the start of each run. The maximum temporal resolution of the CFA system can be evaluated from the transfer function produced by the step test (e.g., Stowasser et al., 2012). At a $6 \mathrm{~cm} \mathrm{~min}^{-1}$ melt rate a periodic $\mathrm{CO}$ signal in the ice with a wavelength of $7 \mathrm{~cm}$ depth can still be detected, although it will be significantly dampened (Fig. S1 in the Supplement).

Finally, the NEEM-2011-S1 ice age scale (Sigl et al., 2013) and the modern-day gas-age-ice-age difference ( $\triangle$ age $)$ for NEEM $(182+3 /-9 \mathrm{yr}$, Buizert et al., 2012), considered as constant along the depth range investigated here, were used to generate the gas age scale.

\subsection{Chemical analysis}

Ice core sample was analyzed continuously by inductively coupled plasma mass spectrometry (ICP-MS) and fluorimetry for a broad range of elements and chemical species

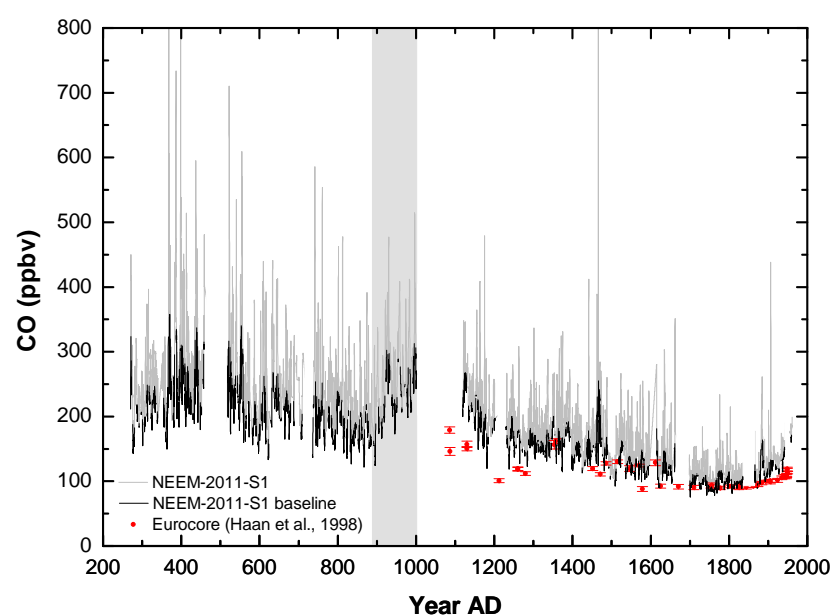

Figure 3. NEEM-2011-S1 continuous CO record over the last $1800 \mathrm{yr}$ (grey and dark). Signal baseline is defined by $0.5 \times \mathrm{MAD}<15 \mathrm{yr}$ running average (dark). $48 \mathrm{ppbv}$ (estimated procedural blank) was subtracted from all $\mathrm{CO}$ concentrations in the NEEM-2011-S1 record. The grey background identifies the depth range where $\mathrm{CO}$ data may be affected by drilling fluid contamination. $\mathrm{CO}$ concentrations from Eurocore (Summit, central Greenland, red dot; Haan et al., 1998) are plotted for comparison. Error bars on Eurocore data represent the $95 \%$ confidence interval. The Eurocore $\mathrm{CO}$ dating and corresponding uncertainties are discussed by Barnola et al. (1995).

during the analytical campaign. These analytical methods have been reported previously (McConnell et al., 2002, 2007; McConnell and Edwards, 2008). In this study, we specifically investigated refractory black carbon (rBC) and ammonium $\left(\mathrm{NH}_{4}^{+}\right)$. Selected ice samples were also measured for discrete chemical analysis at LGGE (Grenoble, France), including DOC, formaldehyde (HCHO), and $\mathrm{NH}_{4}^{+}$. The methods used for these analyses are described in a companion paper (Legrand et al., 2013a).

\section{Results and discussion}

The full CO record available from the NEEM-2011-S1 core is reported in Fig. 3 and plotted versus the mean gas age. CO levels reconstructed over the last 1800 yr exhibit elevated and highly variable values, which range from 75 to $818 \mathrm{ppbv}$. One event peaks beyond this range at $1327 \mathrm{ppbv}$ in $1465 \mathrm{AD}$. In Sect. 3.1 we discuss the baseline levels of the record and the abrupt CO spike patterns observed. The key question of whether an atmospheric signal can be extracted from the low frequency variability of the NEEM-2011-S1 record's baseline is addressed in Sect. 3.2. In situ production is discussed as the process likely driving the abrupt CO spikes in Sect. 3.3. Finally, Sect. 3.4 investigates possible processes involved in $\mathrm{CO}$ in situ production. 


\subsection{A continuous $\mathrm{CO}$ record along the NEEM-2011-S1 core}

\subsubsection{CO baseline levels}

We identified the NEEM-2011-S1 CO baseline by considering only data lower than a cutoff value of running median $0.5^{*} \mathrm{MAD}$, where the running median has a window of $15 \mathrm{yr}$ and MAD is the median absolute deviation. A window of $15 \mathrm{yr}$ corresponds to a time interval shorter than the full width at half maximum of the $\mathrm{CO}$ age distribution at the NEEM close-off (Fig. S4 in the Supplement in Petrenko et al., 2013). Note that any window length between 10 and $20 \mathrm{yr}$ produces a very similar spike identification. MAD values were calculated separately for the 1680-1950 AD, the 1100-1680 AD, and the 250-1100 AD sections of the record to account for increasing variability in the CO data. The NEEM-2011-S1 $\mathrm{CO}$ record exhibits the highest baseline values at the deepest depths analyzed (226 $\pm 37 \mathrm{ppbv})$ between 280 and $430 \mathrm{AD}$ (379 to $409 \mathrm{~m}$ depth). A decrease of $\sim 0.05 \mathrm{ppbv} \mathrm{yr}^{-1}$ in baseline CO from the bottom of the NEEM-2011-S1 core to a period of low, relatively stable concentrations occurring between 1700 and $1840 \mathrm{AD}$ can then be observed. Superimposed on this decreasing trend are two features, increasing $\mathrm{CO}$ concentrations between 900 and $1000 \mathrm{AD}$ and decreasing CO levels from 1100 to $1200 \mathrm{AD}$, suggesting a period of higher CO between 900 and 1200 AD. However, we cannot rule out that drilling fluid contamination affected this specific part of the record, which is highlighted with a grey background on Fig. 3 (see Sect. 3.2.1). No data were collected from ice core sticks dated 1000-1100 AD due to analytical problems. Finally, baseline CO shows a rapid increase at a rate of $1 \mathrm{ppbv} \mathrm{yr}^{-1}$ from its minimum in $1840 \mathrm{AD}$ to closeoff depth (i.e., $78 \mathrm{~m}$; 1934 AD).

\subsubsection{Abrupt CO spikes}

Figure 3 also reveals the occurrence of multiple spikes along the NEEM-2011-S1 CO record that are too abrupt and rapid to be preserved atmospheric signals due to the smoothing effect of firn processes (e.g., Schwander et al., 1993). We identify 96 events of highly enhanced $\mathrm{CO}$ concentrations ( $>2 *$ MAD above $15 \mathrm{yr}$ running median) along the NEEM2011-S1 record. The occurrence of abrupt CO spikes increased with depth along the NEEM-2011-S1 core, with 29 and 38 spikes observed in the $80-200 \mathrm{~m}$ and the 300 $400 \mathrm{~m}$ depth ranges, respectively. Interestingly, the amplitude of these spikes also increases with depth: the median absolute deviation is 17,35 , and 48 ppbv over the age intervals 1950 $1680,1680-1100$, and 1100-250 AD, respectively. Mean CO spike concentrations observed were $120 \pm 20,190 \pm 36$, and $278 \pm 57 \mathrm{ppbv}( \pm 1 \sigma)$ for the age intervals $1950-1680,1680$ 1100 , and 1100-250 AD, respectively. Similar increasing variability with depth in $\mathrm{CO}$ concentration has been reported previously by Haan et al. (1998) over the Eurocore archive.
The true maximum CO mixing ratios in the NEEM-2011$\mathrm{S} 1$ ice are expected to be higher as these $\mathrm{CO}$ spikes have been smoothed by the CFA system. A direct comparison between continuous $\mathrm{CH}_{4}$, measured simultaneously with $\mathrm{CO}$ along the NEEM-2011-S1 core, and discrete $\mathrm{CH}_{4}$ measurement ratios has been reported by Rhodes et al. (2013). These authors demonstrated that continuous measurement could induce a dampening of $38 \%$ of the $\mathrm{CH}_{4}$ amplitude for smallscale $(<100 \mathrm{~cm}$ depth) features: a specific methane spike of 67 ppb was measured with the CFA system, but discrete measurements resolved a $107 \mathrm{ppb}$ spike. Assuming that similar smoothing affects $\mathrm{CO}$ spikes, maximum $\mathrm{CO}$ concentrations for the three age intervals described before would be $\sim 193$, $\sim 306$, and $\sim 448$ ppbv, respectively.

The CO spikes are always extremely abrupt (i.e., occurring within $2 \mathrm{yr}$ ) and are limited to specific ice layers, suggesting that $\mathrm{CO}$ production is related to the chemical or microbiological content of the ice. The horizontal extent of the ice regions showing enhanced CO cannot be quantified. However, similar CO signals (as well as methane spikes, see Rhodes et al., 2013) were recorded in parallel ice core sticks ( $M$ and B cuts, e.g., Fig. 2) encompassing a horizontal distance of $6.8 \mathrm{~cm}$.

\subsection{Comparison with central Greenland $\mathrm{CO}$ records}

Figure 3 provides a direct comparison of the NEEM-S12011 and the Eurocore (Haan and Raynaud, 1998) records for the last millennium (i.e., 1200-1950 AD). Eurocore was drilled at Summit, central Greenland $\left(75.58^{\circ} \mathrm{N}, 37.54^{\circ} \mathrm{W}\right.$; elevation: $3240 \mathrm{~m}$; mean annual temperature: $-32^{\circ} \mathrm{C}$ ). Before $1600 \mathrm{AD}$, the Eurocore $\mathrm{CO}$ record exhibits elevated and variable CO levels (100-180 ppbv) attributed to in situ production (Haan and Raynaud, 1998). The Eurocore CO is stable at $\sim 90 \mathrm{ppbv}$ between 1600 and $1850 \mathrm{AD}$ and increases from 90 to $110 \mathrm{ppbv}$ between 1850 and $1950 \mathrm{AD}$. From 250 to $1680 \mathrm{AD}$, baseline NEEM-2011-S1 CO concentrations are higher than those observed on the Eurocore for the stable 1600-1850 AD period, and even higher than those reported recently by direct atmospheric monitoring conducted at remote northern latitudes (see Sect. 1). NEEM2011-S1 CO levels before $1680 \mathrm{AD}$ are also almost always higher than the value of $\sim 158 \mathrm{ppbv}$ - the peak in $\mathrm{CO}$ concentrations reconstructed over Greenland using three different firn air archives (Petrenko et al., 2013). Between 1680 and $1950 \mathrm{AD}$, the agreement between NEEM-2011-S1 baseline and Eurocore CO records improves. Specifically, the mean NEEM-2011-S1 CO is $100 \pm 16$ ppbv between 1600 and 1850 and increases from $\sim 90$ to $\sim 120 \mathrm{ppbv}$ between 1850 and 1950 AD. Thus, the NEEM-2011-S1 data reproduce the increasing trend in $\mathrm{CO}$ concentration starting in $1850 \mathrm{AD}$ revealed by the Eurocore data.

In summary, the most recent $300 \mathrm{yr}$ section of the NEEM2011-S1 baseline CO record mirrors the trends (if not the absolute values) in the past atmospheric CO signal, specifically the 1850-1950 AD increase in concentration. Despite this 
promising trend, the NEEM-2011-S1 data are highly variable and it is difficult to isolate a baseline that we can confidently interpret as the atmospheric CO history because the abrupt $\mathrm{CO}$ spikes are so prevalent.

\subsection{Is the CO variability driven by drilling and post-drilling processes?}

\subsubsection{Impact of drilling fluid}

Fluid that is rich in organic compounds (Estisol 240 and Coasol) was used during the drilling of the NEEM-2011-S1 core at depths below $80 \mathrm{~m}$. Thus, one needs to investigate if the CO patterns observed along the NEEM-2011-S1 core, i.e., both spikes and an elevated baseline compared to previous studies, are related to contamination from the drilling fluid. A test involving analysis of air inside the head space of an Estisol 240 drill fluid container recorded excess CO concentrations of $700 \mathrm{ppbv}$. Interestingly, the same test recorded an excess $\mathrm{CH}_{4}$ concentration of only $40 \mathrm{ppbv}$, confirming the more limited impact of drilling fluid on methane measurements (Rhodes et al., 2013). To characterize how drilling fluid may have disturbed the $\mathrm{CO}$ record, we performed DOC analysis on a unique sample that was slightly cracked and therefore likely to contain drill fluid residue. We observed DOC concentrations $>600 \mathrm{ppbC}-$ an elevated value confirming contamination. Each NEEM-2011-S1 ice stick was thus inspected for fractures before melting and affected sections were removed prior to melting. However, a continuous, $43 \mathrm{~m}$ section of the core (249-292 m depth) showed many drilling cracks and was analyzed (grey shading on Fig. 3). Over this interval, the NEEM-2011-S1 record shows an increase in $\mathrm{CO}$ baseline concentrations and other chemical tracers also showed unusual baseline levels. Unfortunately, the gas record from this section dates from the medieval climatic optimum, a period of warmer climate and a change in fire regime (Marlon et al., 2008), where CO investigation would have been particularly pertinent. We note that these cracks did not alter the $\mathrm{CH}_{4}$ record preserved in the NEEM2011-S1 core, as evidenced by the good agreement between NEEM-2011-S1 and GISP2 discrete $\mathrm{CH}_{4}$ data (Rhodes et al., 2013).

Aside from this troublesome section of ice core, the physical quality of the core increased with depth. The frequency and magnitude of $\mathrm{CO}$ spikes were also observed to increase with depth, suggesting these trends are not related to drill fluid. DOC analysis shows very low concentrations on uncracked samples - typically lower than $20 \mathrm{ppbC}$ (see Sect. 3.4.1). Furthermore, excellent repeatability was observed in parallel M and B ice sticks (Fig. 2). We thus conclude that $\mathrm{CO}$ contamination induced by drilling fluid only affected the 249-292 m depth section, and cannot explain the variability observed at other depths along the NEEM-2011S1 record.

\subsubsection{Does continuous laboratory melting drive CO production?}

Haan el al. (2001) observed CO production within an alpine snowpack under light conditions, but no $\mathrm{CO}$ production during dark conditions. In water of the upper St. Lawrence estuarine system, Zhang et al. (2008) observed that dark and photolytic production of $\mathrm{CO}$ are the same order of magnitude. To evaluate the hypothesis that $\mathrm{CO}$ variability observed along the NEEM-2011-S1 core may be related to photochemically driven $\mathrm{CO}$ production during the melting and concomitant extraction of precursors that exist in the ice, $4 \mathrm{~m}$ of ice from a core drilled without fluid at the D4 site (Greenland; $2713 \mathrm{~m}$ a.s.l.; $71.4^{\circ} \mathrm{N}, 44.0^{\circ} \mathrm{W}$ ) were melted in September 2013 on the DRI continuous melting system, in conditions similar to those used two years earlier for the NEEM-2011-S1 core. Ice sticks parallel to these $4 \mathrm{~m}$ were melted two weeks later with all laboratories kept in darkness. Both CO records obtained during regular melting and dark melting are shown on Fig. S2 in the Supplement.

Although we report here only $4 \mathrm{~m}$ of continuous CO measurements along the D4 core, these data show similarities with the NEEM-2011-S1 record. Large and abrupt increases in $\mathrm{CO}$ are observed, i.e., $\mathrm{CO}$ increases by $\sim 170 \mathrm{ppbv}$ within a $30 \mathrm{~cm}$ depth range at $103.5 \mathrm{~m}$ depth. We thus suggest that similar artifacts involving $\mathrm{CO}$ production during melting should affect both the NEEM-2011-S1 and the D4 ice. A constant $5 \mathrm{~cm}$ offset has been applied to the dark-record depth scale used on Fig. S2 in the Supplement. CO concentrations measured on both parallel ice sections were averaged by binning over $5 \mathrm{~cm}$-long intervals (Fig. S2 in the Supplement, inset) and show excellent correlation $\left(r^{2}=0.88, p<0.01\right)$ between averaged $\mathrm{CO}$ from light melting versus averaged $\mathrm{CO}$ from dark melting. Light and dark melting conditions produced similar $\mathrm{CO}$ patterns, providing evidence that the $\mathrm{CO}$ spikes do not involve photolytic production occurring in the sampling lines between the melter head and the CFA extraction box. To further investigate if the CFA analytical system could somehow induce $\mathrm{CO}$ production within the melted ice, a melted D4 sample was collected after gas extraction (i.e., downstream of the MicroModule membrane) and recirculated within one hour as degassed blank water in the full-loop mode. We observed similar CO levels to the DI water blank. Finally, although we cannot fully exclude that $\mathrm{CO}$ production occurs after ice melting, the unknown processes involved would require fast kinetics $(<3 \mathrm{~min})$ and would be independent of light.

It is also unlikely that $\mathrm{CO}$ would be produced within ice during core storage. The NEEM-S1-2011 was analyzed only three months after drilling, and already showed abrupt $\mathrm{CO}$ spikes. On the other hand, the D4 ice was analyzed ten years after drilling, and although we analyzed and discuss here only a $4 \mathrm{~m}$ depth range, it does not reveal $\mathrm{CO}$ mixing ratios higher than found in the NEEM-2011-S1 record. One could also note that Haan et al. (1996) found no in situ production 
in the shallow Eurocore ice while measuring samples $5 \mathrm{yr}$ after the Eurocore drilling. Finally, we conclude that abrupt CO spikes observed along the NEEM-2011-S1 record are likely the result of in situ production that occurs in the glacier itself.

\subsection{Investigating processes driving $\mathrm{CO}$ in situ production}

\subsubsection{Comparing CO and DOC levels: a case study}

Oxidation of organic material produced in biomass burning plumes, and later deposited to the Greenlandic ice cap, has been suggested as an explanation for the elevated and variable $\mathrm{CO}$ concentrations along the Eurocore (Haan and Raynaud, 1998). As a first attempt to relate the ice chemical composition and the $\mathrm{CO}$ spike pattern, we selected a core section (138.8-140.4 m depth) showing elevated $\mathrm{NH}_{4}^{+}$, i.e., enriched with pyrogenic aerosols (Savarino and Legrand, 1998), for an extended measurement array of inorganic and organic compounds and fractions. As a reference, similar analyses were conducted on a deeper section of ice containing low levels of $\mathrm{NH}_{4}^{+}$(296.3-296.9 $\mathrm{m}$ depth, referred to later as the "reference section"). These results are discussed in detail in a companion paper (Legrand et al. 2013a); we only report here discrete analysis of DOC, formaldehyde (HCHO) and $\mathrm{NH}_{4}^{+}$(Fig. 4).

The reference ice section, free from pyrogenic aerosols (blue in Fig. 4), exhibits a clear seasonal $\mathrm{NH}_{4}^{+}$pattern, with winter concentrations $<5 \mathrm{ppb}$ and summer concentrations in the range of 9 to $12 \mathrm{ppb}$. Such variations can be explained by seasonal emissions from soils and vegetation (Fuhrer et al., 1996) and are similar to present-day observations at Summit, Greenland (Dibb et al., 2007). DOC and HCHO concentrations do not show such a seasonal contrast, but rather quite low values averaging $17.9 \pm 9.2 \mathrm{ppbC}$, and $2.2 \pm 0.5 \mathrm{ppb}$, respectively. $\mathrm{rBC}$ ranges between 4 and $12 \mathrm{ng} \mathrm{g}^{-1}$, and CO is $230.7 \pm 21.8 \mathrm{ppbv}$, only slightly above the $224.1 \pm 5.2 \mathrm{ppbv} 15 \mathrm{yr}$ running median over this depth interval. The pyrogenic-aerosol-enriched layer located at $140.15 \mathrm{~m}$ depth (black in Fig. 4) shows clear spikes in both $\mathrm{NH}_{4}^{+}$(maximum of $143 \mathrm{ppbv}$ ) and DOC (maximum of $116 \mathrm{ppbC})$. HCHO averages $2.8 \pm 0.5 \mathrm{ppb}$ over the section investigated, and $\mathrm{rBC}$ ranges between 4 and $16 \mathrm{ng} \mathrm{g}^{-1}$. Finally, CO peaks at $84 \mathrm{ppbv}$ above the $15 \mathrm{yr}$ running median as calculated at this depth (Fig. 4).

Although a large fraction of water soluble and insoluble organic carbon may be lost at the surface during postdeposition processes (as reported at the central Greenland station of Summit by Hagler et al., 2007), the amount of DOC still available in the ice ( $>100 \mathrm{ppbC})$ represents an important reservoir of carbon, which can potentially be oxidized to carbon monoxide. The oxidation processes involved are not identified yet, and a better characterization of the speciation of the organic content of the NEEM-2011-S1 ice is required. A first attempt to determine such speciation for the $140.15 \mathrm{~m}$
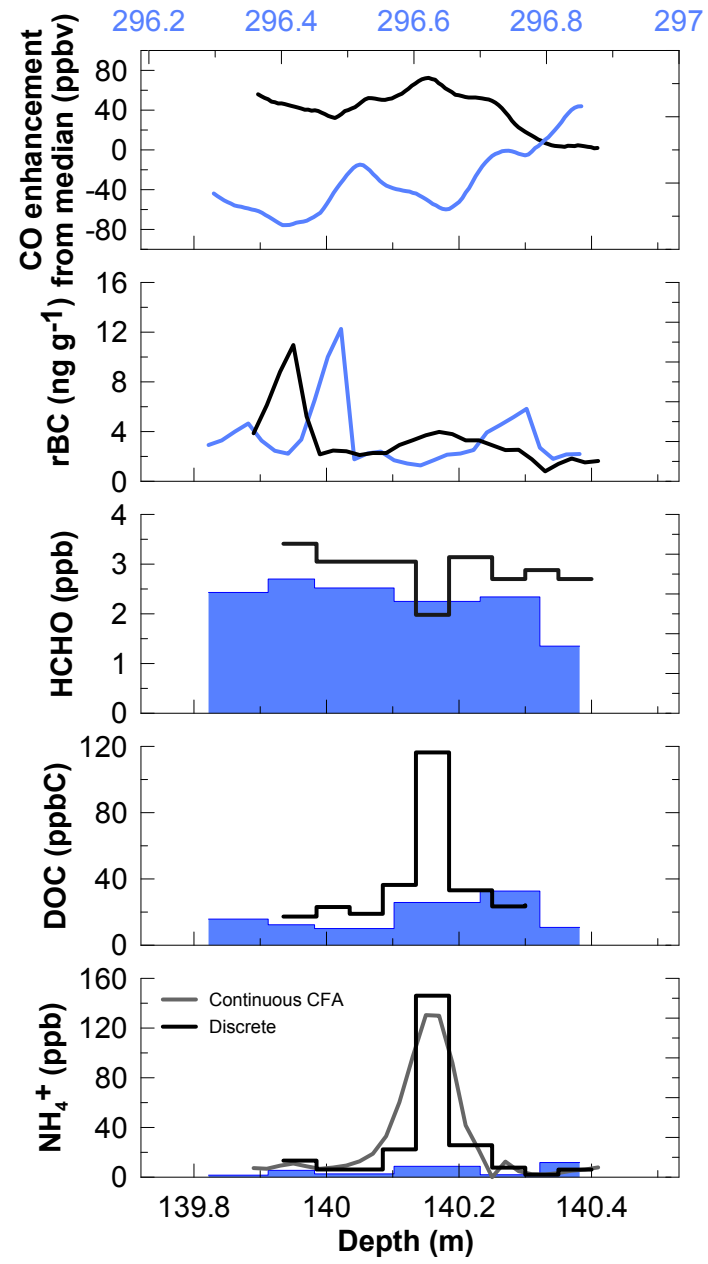

Figure 4. $\mathrm{CO}$ enhancement above the $15 \mathrm{yr}$ running median, rBC, HCHO, DOC, and $\mathrm{NH}_{4}^{+}$over two selected layers of the NEEM-2011-S1 core: a pyrogenic0-aerosols-enriched layer (139.9-140.4 $\mathrm{m}$ depth, black curves, bottom $x$-scale), and a pyrogenic-aerosols-free layer (296.3-296.9 m depth, solid blue curves, top $x$-scale). Both discrete and continuous (CFA-based) $\mathrm{NH}_{4}^{+}$measurements are reported.

depth layer is reported by Legrand et al. (2013a), and reveals that $80 \%$ of the chemical composition of DOC can be identified. Haan et al. (2001) suggested that organic compounds present in snow precipitation are the major substrate for the photochemical $\mathrm{CO}$ production observed in freshly fallen alpine snow. Interestingly, photo-induced production of $\mathrm{CO}$ within the deep ice cannot be ruled out. A few laboratory studies have suggested that the photodegradation of dissolved organic matter trapped in ice cores by ultraviolet Cerenkov radiation from cosmic muons can account for the anomalous $\mathrm{CO}$ and $\mathrm{CO}_{2}$ levels (Colussi and Hoffmann, 2003; Guzman et al., 2007), and the correlation between them (e.g., Haan and Raynaud, 1998).

While DOC shows a clear increase in concentration only in the ice layer affected by biomass burning, $\mathrm{HCHO}$ and 


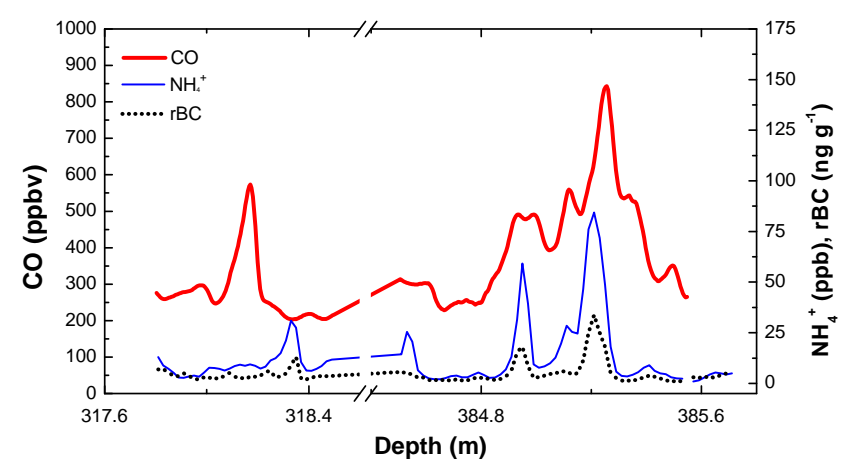

Figure 5. $\mathrm{CO}, \mathrm{NH}_{4}^{+}$and $\mathrm{rBC}$ concentrations for two isolated depth sections that show contrasting relationships between $\mathrm{CO}$ and the pyrogenic aerosols. The depth uncertainty is $6 \mathrm{~cm}$.

rBC exhibit similar patterns in both sections. HCHO is slightly but significantly higher (accuracy of HCHO analysis is $0.1 \mathrm{ppb}$; Preunkert and Legrand, 2013) in the ice layer affected by biomass burning. Therefore, it is possible that an initial enrichment in $\mathrm{HCHO}$ co-located with the $\mathrm{NH}_{4}^{+}$peak has diffused within the ice, as suggested by Guerinot (2000). The increase in amplitude of CO spikes with depth suggests that slow kinetic processes may be involved and that $\mathrm{CO}$ production is occurring throughout the $410 \mathrm{~m}$-depth core. We hypothesize that $\mathrm{HCHO}$ has a limited contribution to the likely CO in situ production within the NEEM-S1-2011 core because it is either absent or has diffused at a depth of only $140 \mathrm{~m}$. Our results therefore do not support a significant role for $\mathrm{HCHO}$, as previously reported in alpine seasonal snowpacks (Haan et al., 2001). Extending continuous HCHO measurements over a longer section including $\mathrm{NH}_{4}^{+}$peaks would be required to be conclusive.

Oxidation, possibly photoinduced, of organic compounds initially enclosed in the ice may produce $\mathrm{CO}$ in situ (e.g., within the $140.2 \mathrm{~m}$-depth layer), and we know that biomass burning is a source of organic compounds at the NEEM site (Fig. 4; see also Legrand et al., 2013a). We thus suggest that the NEEM-2011-S1 CO record appears to be influenced by pyrogenic aerosol deposition and therefore past fire history.

\subsubsection{Full record comparison with biomass burning tracers}

Both $\mathrm{NH}_{4}^{+}$and $\mathrm{rBC}$ have been identified as good tracers of biomass burning (Legrand et al., 1992; Savarino and Legrand, 1998; McConnell et al., 2007). We thus investigated co-variations of $\mathrm{CO}$ with $\mathrm{NH}_{4}^{+}$and $\mathrm{rBC}$ along the entire NEEM-2011-S1 core to better evaluate how past fire history might drive the highly variable $\mathrm{CO}$ record. Figure 5 reports $\mathrm{NH}_{4}^{+}$and $\mathrm{rBC}$ concentrations for two deep core sections showing enhanced CO levels, at depth intervals of 317.7318.5 and $384.6-385.7 \mathrm{~m}$, respectively. These two sections reveal different patterns. At $318.2 \mathrm{~m}$ depth, $\mathrm{CO}$ increases up
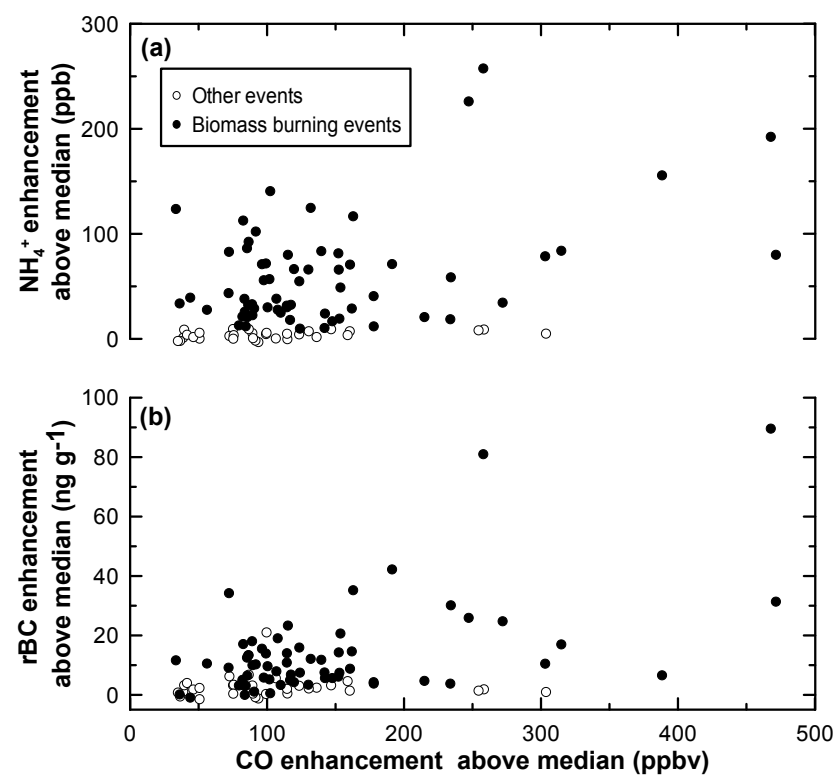

Figure 6. CO concentration enhancements above median values for the 96 spikes selected along the NEEM-2011-S1 record, as a function of $\mathrm{NH}_{4}^{+}$(a) and $\mathrm{rBC}(\mathbf{b})$ concentrations. Both $\mathrm{NH}_{4}^{+}$and $\mathrm{rBC}$ are shown as enhancement levels above their corresponding median. Ice layers enriched with pyrogenic aerosols (closed circles) are identified when $\left[\mathrm{NH}_{4}^{+}\right]>18$ ppbv (Savarino and Legrand, 1998).

to $600 \mathrm{ppbv}$, but $\mathrm{NH}_{4}^{+}$and $\mathrm{rBC}$ remain at relatively low levels (8.6 ppb and $2.6 \mathrm{ng} \mathrm{g}^{-1}$, respectively); conversely we observed at $385.2 \mathrm{~m}$ depth a concomitant increase of $\mathrm{CO}, \mathrm{NH}_{4}^{+}$, and $\mathrm{rBC}$, reaching $800 \mathrm{pbbv}, 83 \mathrm{ppb}$, and $32 \mathrm{ng} \mathrm{g}^{-1}$, respectively. As discussed in Sect. 2.5.3, the uncertainty on the gas-data depth scaling is about $6 \mathrm{~cm}$. Such uncertainty explains the slight depth misalignment between $\mathrm{CO}$ and liquid phase records (i.e., $\mathrm{NH}_{4}^{+}$and $\mathrm{rBC}$ ) at $385.2 \mathrm{~m}$ depth, although it cannot line up the CO peak observed at $318.2 \mathrm{~m}$ with any increases in $\mathrm{NH}_{4}^{+}$or $\mathrm{rBC}$. The extensive study by Savarino and Legrand (1998) concluded that an $\mathrm{NH}_{4}^{+}$spike above a threshold value of $18 \mathrm{ppb}$ in the Eurocore archive unambiguously identified a pyrogenic-aerosol-rich layer. While the CO spike observed at $385.2 \mathrm{~m}$ depth is observed in an ice layer enriched by pyrogenic aerosol $\left(\left[\mathrm{NH}_{4}^{+}\right]<18 \mathrm{ppb}\right)$, the $\mathrm{CO}$ increase occurring at $318.2 \mathrm{~m}$ depth cannot be related to any existing tracer of a biomass-burning event. This suggests that not all CO enhancements along the NEEM-S1-2011 are driven by the same process.

We calculated $\mathrm{NH}_{4}^{+}$and $\mathrm{rBC}$ enhancements above their median values (median values estimated from the complete data set, $4.1 \mathrm{ppb}$ for $\mathrm{NH}_{4}^{+}$and $2.3 \mathrm{ng} \mathrm{g}^{-1}$ for $\mathrm{rBC}$ ) during the 96 enhanced-CO events. Figure 6 plots $\mathrm{CO}$ versus $\mathrm{NH}_{4}^{+}$and $\mathrm{rBC}$ during these enhanced-CO events. We further identified $\mathrm{CO}$ spikes related to biomass-burning events by considering $\mathrm{NH}_{4}^{+}$above the biomass-burning threshold value of $18 \mathrm{ppb}$ identified by Savarino and Legrand (1998). Interestingly, this 
analysis reveals that $32 \%$ of the elevated-CO events occurred in ice layers devoid of pyrogenic aerosols as traced by $\mathrm{rBC}$ and $\mathrm{NH}_{4}^{+}$(e.g., the event observed at $318.2 \mathrm{~m}$ depth, Fig. 5). Furthermore, when considering the $68 \%$ of events associated with biomass-burning-related aerosol deposition, no significant correlations between $\mathrm{CO}$ and $\mathrm{rBC}$ or $\mathrm{NH}_{4}^{+}$can be observed. Neither $\mathrm{NH}_{4}^{+}$or $\mathrm{rBC}$ showed a monotonic increasing trend with depth, as observed for CO.

Finally, investigating high resolution $\mathrm{CO}, \mathrm{NH}_{4}^{+}$and $\mathrm{rBC}$ data confirms that multiple processes are involved in the $\mathrm{CO}$ production within the NEEM-2011-S1 ice core. Abrupt CO spikes may be related to pyrogenic-aerosols deposition, but other factors controlling the substrate availability or oxidation pathway may also exist.

\subsubsection{Comparison with $\mathrm{CO}$ record from an alpine core}

We investigated $\mathrm{CO}, \mathrm{NH}_{4}^{+}$, and DOC from ice cores drilled at a mid-latitude site to ascertain whether similar relationships between ice chemistry and in situ $\mathrm{CO}$ production that are observed along the NEEM-2011-S1 core also occur in other glaciers. Col du Dome (CDD) is an elevated (4250 m a.s.1.) site located in the vicinity of the Mont Blanc summit in France. Eleven discrete samples were analyzed in 2001 from the $\mathrm{C} 10$ and $\mathrm{C} 11$ cores for $\mathrm{CO}$ concentrations, following the protocol of Haan et al. (1996). $\mathrm{NH}_{4}^{+}$and DOC were analyzed in the CDK core (Preunkert and Legrand, 2013) and reported as splined trends in Table 2 to account for uncertainties in relative depth scaling between CDK and C10/C11 cores, respectively.

Two summertime and two wintertime ice layers were identified using $\mathrm{NH}_{4}^{+}$and were analyzed for $\mathrm{CO}$ (Table 2). We specifically investigated winter 1975 and summer 1976. CO concentrations in summer layers were about one order of magnitude higher compared to winter layers, with summer levels always above $1000 \mathrm{ppbv}$ and winter levels in the range of 300 to $500 \mathrm{ppbv}$. Along the $340 \mathrm{~m}$-long NEEM-2011-S1 core, which spans the last $1800 \mathrm{yr}$ and was continuously analyzed, only $11 \mathrm{CO}$ spikes with concentrations $>500 \mathrm{ppbv}$ were identified, and only one event showed $\mathrm{CO}>1000$ ppbv. In situ production of $\mathrm{CO}$ is clearly enhanced in the midlatitude, alpine CDD ice compared to the high-latitude, polar NEEM ice. These high CO levels in the CDD ice were observed only $\sim 15 \mathrm{~m}$ below the close-off depth. We suggest that slow kinetic processes may build up $\mathrm{CO}$ with depth in the NEEM ice but in situ production at CDD happens much faster.

The reason for a higher production of $\mathrm{CO}$ at $\mathrm{CDD}$ may include surface melting and percolation. Liquid-phase chemical production of $\mathrm{CO}$ may occur and explain the higher $\mathrm{CO}$ concentrations in summer layers compared to winter layers. However, refrozen layers and melt water percolation within CDD ice cores occur only in summer and are limited to a few centimeters, corresponding to a few weeks of accumulation (Preunkert et al., 2000, and references therein). Another
Table 2. CO concentration measured at 11 depths in the $\mathrm{C} 10$ and $\mathrm{C} 11 \mathrm{Col}$ du Dome cores. DOC and $\mathrm{NH}_{4}^{+}$were measured in the $\mathrm{CDK}$ core, also drilled at $\mathrm{Col}$ du Dome. We report splined $\mathrm{NH}_{4}^{+}$ and DOC data according to Preunkert and Legrand (2013), to represent seasonal averages. Dating of the C10, C11, and CDK cores has been reported by Preunkert et al. (2000) and Legrand et al. (2007), respectively.

\begin{tabular}{lrlllll}
\hline Core & $\begin{array}{r}\text { Depth } \\
(\mathrm{m})\end{array}$ & $\begin{array}{l}\text { Ice age } \\
(\mathrm{AD})\end{array}$ & $\begin{array}{l}\mathrm{CO} \\
(\mathrm{ppb})\end{array}$ & $\begin{array}{l}\mathrm{NH}_{4}^{+} \\
(\mathrm{ppb}) \\
\text { spline }\end{array}$ & $\begin{array}{l}\text { DOC } \\
(\mathrm{ppbC}) \\
\text { spline }\end{array}$ & Season \\
\hline $\mathrm{C} 10$ & 69.0 & 1976 & $1063 \pm 16$ & & & \\
\hline $\mathrm{C} 10$ & 73.15 & 1976 & $1196 \pm 25$ & & & Summer \\
$\mathrm{C} 10$ & 73.20 & 1976 & $3790 \pm 7$ & 147 & 210 & \\
$\mathrm{C} 10$ & 73.27 & 1976 & $3463 \pm 130$ & & & \\
$\mathrm{C} 11$ & 109.3 & $1939-1947$ & $3801 \pm 76$ & 69 & 95 & Winter \\
\hline $\mathrm{C} 10$ & 71.2 & $1975 / 1976$ & $377 \pm 11$ & 78 & 86 & \\
$\mathrm{C} 10$ & 72.1 & $1975 / 1976$ & $473 \pm 7$ & 78 & 86 & 44 \\
$\mathrm{C} 11$ & 126.7 & $1912-1925$ & $359 \pm 9$ & 40 & 44 & \\
\hline $\mathrm{C} 11$ & 99.9 & 1957 & $2003 \pm 79$ & n.d. & n.d. & \\
$\mathrm{C} 11$ & 136.6 & $<1910$ & $1590 \pm 42$ & n.d. & n.d. & n.d. \\
$\mathrm{C} 11$ & 137.5 & $<1910$ & $2616 \pm 87$ & n.d. & n.d. & \\
\hline
\end{tabular}

possible explanation is the presence of much more organic material in the CDD ice compared to the NEEM ice. We found $116 \mathrm{ppbC}$ of DOC in a NEEM-2011-S1 layer affected by deposition of pyrogenic aerosols. DOC in CDD ice increases by about a factor of two between winter and summer and its decadal averaged levels have doubled since the early 1900s (Legrand et al., 2013b). Thus, one could argue than more $\mathrm{CO}$ can be produced if more DOC is available (i.e., just below the close-off), but similarly to the NEEM2011-S1 record we expect more CO at deeper levels considering that $\mathrm{CO}$ in situ production is driven by slow kinetic processes. Overall, these data confirm that $\mathrm{CO}$ in situ production can be greatly enhanced in middle-latitude glaciers. More analysis is required to understand how and why the processes of $\mathrm{CO}$ production may differ at different sites.

\section{Conclusions}

For the first time, a high-resolution, continuous profile of carbon monoxide concentrations has been measured along a 340 m-long ice core, the NEEM-2011-S1 archive. The measurements along the complete ice core were carried out in only a few weeks by coupling an OF-CEAS laser spectrometer with a continuous melting system. We demonstrate the good external precision $(7.8 \mathrm{ppbv})$ of this continuous $\mathrm{CO}$ analysis, based on comparison of replicate ice core sticks. However, the accuracy needs to be improved by the optimization of our calibration methods for future applications of this method. The elevated procedural CO blanks of the system and the lack of correction for CO losses currently preclude reconstruction of past absolute atmospheric $\mathrm{CO}$ concentrations from ice cores minimally affected by in situ 
production (e.g., Antarctica ice samples). Continuous measurements should be performed together with discrete analyses to allow validation of any future attempt at absolute calibration. The system is suitable for identifying ice layers that are promising targets of more accurate discrete measurements of $\mathrm{CO}$ and possibly $\mathrm{CO}$ isotopes.

The NEEM-2011-S1 CO record exhibits concentrations ranging from 75 to $1327 \mathrm{ppbv}$, which are too high and variable to be interpreted as changes in atmospheric CO. The baseline concentration trends reconstructed over the period spanning 1650-1950 AD, however, agree with CO signals retrieved from the discontinuous Eurocore CO profile (Haan and Raynaud, 1998). The good reproducibility obtained from parallel ice sticks suggest that the NEEM-2011-S1 highly variable $\mathrm{CO}$ patterns do exist in the ice itself, although the unlikely possibility of rapid $\mathrm{CO}$ production in the meltwater stream cannot be excluded.

Sixty-eight percent of the elevated CO spikes along the NEEM-2011-S1 core were observed in thin ice layers enriched with the pyrogenic aerosols $\mathrm{rBC}$ and $\mathrm{NH}_{4}^{+}$. Such aerosols, originating from boreal biomass-burning emissions, contain an important organic fraction. Oxidation, possibly photoinduced dissociation, of organic compounds initially enclosed in the ice may produce $\mathrm{CO}$ in situ, resulting in the elevated CO spikes. However, the NEEM-2011S1 record also reveals an increase with depth in baseline CO levels and the baseline level remains high for ice layers depleted of DOC. Although oxidation of organic matter is a likely mechanism for $\mathrm{CO}$ in situ production, it is probably not the only mechanism involved. Finally we suggest that biomass burning partially drives the in situ production of $\mathrm{CO}$ in the NEEM-2011-S1 core, but our study also highlights the complexity of the processes leading to in situ production of $\mathrm{CO}$ in ice cores.

Investigation of Greenland archives is necessary to document past atmospheric $\mathrm{CO}$ from the Northern Hemisphere. We advocate prioritizing measurements at Greenland sites where accumulation rates are high. Thick winter layers with low concentrations of organic precursors should result in minimal in situ $\mathrm{CO}$ production. Coupled with a suite of chemical analyses, such records should enable in situproduced $\mathrm{CO}$ and the atmospheric $\mathrm{CO}$ signal preserved in the ice to be disentangled. However, future studies may need to better characterize the likely processes involved in $\mathrm{CO}$ in situ production. Finally, Antarctic ice archives with low impurity levels should also be investigated, as the ice may contain an unperturbed atmospheric record of carbon monoxide representative of the Southern Hemisphere.

The Supplement related to this article is available online at doi:10.5194/cp-10-987-2014-supplement.
Acknowledgements. This work was supported by the French ANR programs RPD COCLICO (ANR-10-RPDOC-002-01) and NEEM (ANR-07-VULN-09-001), and by the EU FP7 IP PEGASOS (FP7ENV-2010/265148). Support was also supplied by the US National Science Foundation (NSF) Office of Polar Programs (OPP) grants \#0944552 and \#0909541, and NSF Partnerships in International Research and Education (PIRE) grant \#0968391. It received funding from the European Research Council under the European Community's Seventh Framework Programme FP7/2007-2013 Grant Agreement \#291062 (project ICE \& LASERS). Grateful thanks go to Olivia Maselli, Larry Layman, Daniel Pasteris, Michael Sigl, and other members of the DRI team who assisted with the measurement campaign. We thank F. Candaudap and R. Blanchard for assistance with Col du Dome CO measurements. We appreciate the assistance of the NEEM community for logistics, drilling, science, and other support. In particular, we thank S.-B. Hansen, T. Popp, D. Mandeno, M. Leonhardt, and A. Moy and others for drilling the NEEM-2011-S1 core. We also thank A. Svensson, S. Kipfstuhl, and other NEEM scientists and students in the science trench for assistance in processing the core in the field. We thank the three anonymous reviewers for their careful reading of our manuscript and their many insightful comments and suggestions. The NEEM project is directed by the Center for Ice and Climate at the Niels Bohr Institute, Copenhagen, and the US NSF OPP. It is supported by funding agencies and institutions in Belgium (FNRS-CFB and FWO), Canada (NRCan/GSC), China (CAS), Denmark (FIST), France (IPEV, CNRS/INSU, CEA and ANR), Germany (AWI), Iceland (RannIs), Japan (NIPR), Korea (KOPRI), The Netherlands (NWO/ALW), Sweden (VR), Switzerland (SNF), United Kingdom (NERC), and the USA (US NSF, OPP).

Edited by: K. Kawamura

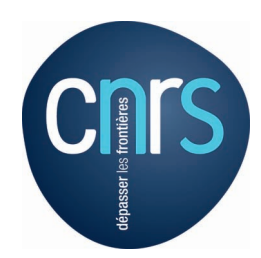

The publication of this article is financed by CNRS-INSU.

\section{References}

Allan, D.: Statistics of atomic frequency standards, Proc. IEEE, 54, 221-230, 1966.

Assonov, S. S., Brenninkmeijer, C. A. M., Jöckel, P., Mulvaney, R., Bernard, S., and Chappellaz, J.: Evidence for a CO increase in the SH during the 20th century based on firn air samples from Berkner Island, Antarctica, Atmos. Chem. Phys., 7, 295-308, doi:10.5194/acp-7-295-2007, 2007.

Barnola, J. M., Anklin, M., Porcheron, J., Raynaud, D., Schwander, J., and Stauffer, B.: $\mathrm{CO}_{2}$ evolution during the last millennium as recorded by Antarctic and Greenland ice, Tellus B, 47, 264-272, 1995.

Bigler, M., Svensson, A., Kettner, E., Vallelonga, P., Nielsen, M. E., and Steffensen, J. P.: Optimization of high-resolution continuous flow analysis for transient climate signals in ice cores, Environ. Sci. Technol., 45, 4483-4489, doi:10.1021/es200118j, 2011. 
Buizert, C., Martinerie, P., Petrenko, V. V., Severinghaus, J. P., Trudinger, C. M., Witrant, E., Rosen, J. L., Orsi, A. J., Rubino, M., Etheridge, D. M., Steele, L. P., Hogan, C., Laube, J. C., Sturges, W. T., Levchenko, V. A., Smith, A. M., Levin, I., Conway, T. J., Dlugokencky, E. J., Lang, P. M., Kawamura, K., Jenk, T. M., White, J. W. C., Sowers, T., Schwander, J., and Blunier, T. Gas transport in firn: multiple-tracer characterisation and model intercomparison for NEEM, Northern Greenland, Atmos. Chem. Phys., 12, 4259-4277, doi:10.5194/acp-12-4259-2012, 2012.

Chappellaz, J., Stowasser, C., Blunier, T., Baslev-Clausen, D., Brook, E. J., Dallmayr, R., Faïn, X., Lee, J. E., Mitchell, L. E., Pascual, O., Romanini, D., Rosen, J., and Schüpbach, S.: Highresolution glacial and deglacial record of atmospheric methane by continuous-flow and laser spectrometer analysis along the NEEM ice core, Clim. Past, 9, 2579-2593, doi:10.5194/cp-92579-2013, 2013.

Colussi, A. J. and Hoffmann, M. R.: In situ photolysis of deep ice core contaminants by Cerenkov radiation of cosmic origin, Geophys. Res. Lett., 30, 1195, doi:10.1029/2002g1016112, 2003.

Crutzen, P. J.: Discussion of chemistry of some minor constituents in stratosphere and troposphere, Pure Appl. Geophys., 106, 1385-1399, 1973.

Dibb, J. E., Whitlow, S. I., and Arsenault, M.: Seasonal variations in the soluble ion content of snow at Summit, Greenland: Constraints from three years of daily surface snow samples, Atmos. Environ., 41, 5007-5019, doi:10.1016/j.atmosenv.2006.12.010, 2007

Duncan, B. N., Logan, J. A., Bey, I., Megretskaia, I. A., Yantosca, R. M., Novelli, P. C., Jones, N. B., and Rinsland, C. P.: Global budget of CO, 1988-1997: Source estimates and validation with a global model, J. Geophys. Res.-Atmos., 112, D22301, doi:10.1029/2007jd008459, 2007.

Ferretti, D. F., Miller, J. B., White, J. W. C., Etheridge, D. M., Lassey, K. R., Lowe, D. C., Meure, C. M. M., Dreier, M. F., Trudinger, C. M., van Ommen, T. D., and Langenfelds, R. L.: Unexpected changes to the global methane budget over the past 2000 years, Science, 309, 1714-1717, doi:10.1126/science.1115193, 2005 .

Fuhrer, K., Neftel, A., Anklin, M., Staffelbach, T., and Legrand, M.: High-resolution ammonium ice core record covering a complete glacial-interglacial cycle, J. Geophys. Res.-Atmos., 101, 41474164, doi:10.1029/95jd02903, 1996.

Gkinis, V., Popp, T. J., Blunier, T., Bigler, M., Schüpbach, S., Kettner, E., and Johnsen, S. J.: Water isotopic ratios from a continuously melted ice core sample, Atmos. Meas. Tech., 4, 25312542, doi:10.5194/amt-4-2531-2011, 2011.

Guerinot, G.: Modélisation du vieillissement chimique de panachés de feux de biomasse boreaux, $\mathrm{PhD}$ dissertation of the University of Grenoble, Grenoble, 2000.

Guzman, M. I., Hoffmann, M. R., and Colussi, A. J.: Photolysis of pyruvic acid in ice: Possible relevance to $\mathrm{CO}$ and $\mathrm{CO}_{2}$ ice core record anomalies, J. Geophys. Res.-Atmos., 112, D10123, doi:10.1029/2006jd007886, 2007.

Haan, D. and Raynaud, D.: Ice core record of CO variations during the last two millennia: atmospheric implications and chemical interactions within the Greenland ice, Tellus B, 50, 253-262, 1998.

Haan, D., Martinerie, P., and Raynaud, D.: Ice core data of atmospheric carbon monoxide over Antarctica and Greenland during the last 200 years, Geophys. Res. Lett., 23, 2235-2238, 1996.
Haan, D., Zuo, Y., Gros, V., and Brenninkmeijer, C. A. M.: Photochemical production of carbon monoxide in snow, J. Atmos. Chem., 40, 217-230, 2001.

Hagler, G. S. W., Bergin, M. H., Smith, E. A., Dibb, J. E., Anderson, C., and Steig, E. J.: Particulate and water-soluble carbon measured in recent snow at Summit, Greenland, Geophys. Res. Lett., 34, L16505, doi:10.1029/2007gl030110, 2007.

Karlsdottir, S. and Isaksen, I. S. A.: Changing methane lifetime: Possible cause for reduced growth, Geophys. Res. Lett., 27, 93 96, 2000.

Kaufmann, P. R., Federer, U., Hutterli, M. A., Bigler, M., Schupbach, S., Ruth, U., Schmitt, J., and Stocker, T. F.: An Improved Continuous Flow Analysis System for High-Resolution Field Measurements on Ice Cores, Environ. Sci. Technol., 42, 80448050, doi:10.1021/Es8007722, 2008.

Legrand, M., De Angelis, M., Staffelbach, T., Neftel, A., and Stauffer, B.: Large perturbation of ammonium and organic acids content in the Summit-Greenland ice core: fingerprint from forest fires?, Geophys. Res. Lett., 19, 473-475, 1992.

Legrand, M., Preunkert, S., Schock, M., Cerqueira, M., KasperGiebl, A., Afonso, J., Pio, C., Gelencser, A., and DombrowskiEtchevers, I.: Major $20^{\text {th }}$ century changes of carbonaceous aerosol components (EC, WinOC, DOC, HULIS, carboxylic acids, and cellulose) derived from Alpine ice cores, J. Geophys. Res., 112, D23S11, doi:10.1029/2006jd008080, 2007.

Legrand, M., Preunkert, S., Jourdain, B., Guilhermet, J., Faïn, X., Alekhina, I., and Petit, J. R.: Water-soluble organic carbon in snow and ice deposited at Alpine, Greenland, and Antarctic sites: a critical review of available data and their atmospheric relevance, Clim. Past, 9, 2195-2211, doi:10.5194/cp-9-2195-2013, 2013a.

Legrand, M., Preunkert, S., May, B., Guilhermet, J., Hoffman, H., and Wagenbach, D.: Major 20th century changes of the content and chemical speciation of organic carbon archived in Alpine ice cores: Implications for the long-term change of organic aerosol over Europe, J. Geophys. Res.-Atmos., 118, 3879-3890, doi:10.1002/jgrd.50202, 2013b.

Marlon, J. R., Bartlein, P. J., Carcaillet, C., Gavin, D. G., Harrison, S. P., Higuera, P. E., Joos, F., Power, M. J., and Prentice, I. C.: Climate and human influences on global biomass burning over the past two millennia, Nat. Geosci., 1, 697-702, doi:10.1038/ngeo313, 2008 .

Martinerie, P., Brasseur, G. P., and Granier, C.: The chemicalcomposition of ancient atmospheres - a model study constrained by ice core data, J. Geophys. Res.-Atmos., 100, 14291-14304, 1995.

McConnell, J. R. and Edwards, R.: Coal burning leaves toxic heavy metal legacy in the Arctic, P. Natl. Acad. Sci., 105, 12140-12144, doi:10.1073/pnas.0803564105, 2008.

McConnell, J. R., Lamorey, G. W., Lambert, S. W., and Taylor, K. C.: Continuous ice-core chemical analyses using inductively coupled plasma mass spectrometry, Environ. Sci. Tech., 36, 7-11, doi:10.1021/es011088z, 2002.

McConnell, J. R., Edwards, R., Kok, G. L., Flanner, M. G., Zender, C. S., Saltzman, E. S., Banta, J. R., Pasteris, D. R., Carter, M. M., and Kahl, J. D. W.: 20th-century industrial black carbon emissions altered Arctic climate forcing, Science, 317, 1381-1384, doi:10.1126/science.1144856, 2007. 
Morville, J., Kassi, S., Chenevier, M., and Romanini, D.: Fast, lownoise, mode-by-mode, cavity-enhanced absorption spectroscopy by diode-laser self-locking, Appl. Phys. B, 80, 1027-1038, doi:10.1007/s00340-005-1828-z, 2005.

Novelli, P. C., Connors, V. S., Reichle, H. G., Anderson, B. E., Brenninkmeijer, C. A. M., Brunke, E. G., Doddridge, B. G., Kirchhoff, V., Lam, K. S., Masarie, K. A., Matsuo, T., Parrish, D. D., Scheel, H. E., and Steele, L. P.: An internally consistent set of globally distributed atmospheric carbon monoxide mixing ratios developed using results from an intercomparison of measurements, J. Geophys. Res.-Atmos., 103, 19285-19293, 1998.

Petrenko, V. V., Martinerie, P., Novelli, P., Etheridge, D. M., Levin, I., Wang, Z., Blunier, T., Chappellaz, J., Kaiser, J., Lang, P., Steele, L. P., Hammer, S., Mak, J., Langenfelds, R. L., Schwander, J., Severinghaus, J. P., Witrant, E., Petron, G., Battle, M. O., Forster, G., Sturges, W. T., Lamarque, J.-F., Steffen, K., and White, J. W. C.: A $60 \mathrm{yr}$ record of atmospheric carbon monoxide reconstructed from Greenland firn air, Atmos. Chem. Phys., 13, 7567-7585, doi:10.5194/acp-13-7567-2013, 2013.

Preunkert, S. and Legrand, M.: Towards a quasi-complete reconstruction of past atmospheric aerosol load and composition (organic and inorganic) over Europe since 1920 inferred from Alpine ice cores, Clim. Past, 9, 1403-1416, doi:10.5194/cp-91403-2013, 2013.

Preunkert, S., Wagenbach, D., Legrand, M., and Vincent, C.: Col du Dome (Mt Blanc Massif, French Alps) suitability for ice-core studies in relation with past atmospheric chemistry over Europe, Tellus B, 52, 993-1012, 2000.

Rhodes, R. H., Faïn, X., Stowasser, C., Blunier, T., Chappellaz, J., McConnell, J. R., Mitchell, L. E., and Brook, E. J.: Continuous ice core methane measurements from a late Holocene Greenland ice core: atmospheric and in-situ signals, Earth Planet. Sc. Lett., 368, 9-19, 2013.

Romanini, D., Chenevier, M., Kassi, S., Schmidt, M., Valant, C., Ramonet, M., Lopez, J., and Jost, H. J.: Optical-feedback cavityenhanced absorption: a compact spectrometer for real-time measurement of atmospheric methane, Appl. Phy. B, 83, 659-667, doi:10.1007/s00340-006-2177-2, 2006.
Savarino, J. and Legrand, M.: High northern latitude forest fires and vegetation emissions over the last millennium inferred from the chemistry of a central Greenland ice core, J. Geophys. Res., 103, 8267-8279, 1998.

Schwander, J., Barnola, J.-M., Andrie, C., Leuenberger, M., Ludin, A., Raynaud, D. and Stauffer, B.: The age of the air in the firn and the ice at Summit, Greenland, J. Geophys. Res., 98, 2831-2838, 1993.

Sigl, M., McConnell, J. R., Layman, L., Maselli, O., McGwire, K., Pasteris, D., Jensen, D. D., Steffensen, J. P., Edwards, R., and Mulvaney, R.: A new bipolar ice core record of volcanism from WAIS Divide and NEEM and implications for climate forcing of the last 2000 years, J. Geophys. Res., 118, 1151-1169, doi:10.1029/2012JD018603, 2013.

Stowasser, C., Buizert, C., Gkinis, V., Chappellaz, J., Schüpbach, S., Bigler, M., Faïn, X., Sperlich, P., Baumgartner, M., Schilt, A., and Blunier, T.: Continuous measurements of methane mixing ratios from ice cores, Atmos. Meas. Tech., 5, 999-1013, doi:10.5194/amt-5-999-2012, 2012.

Valdes, P. J., Beerling, D. J., and Johnson, C. E.: The ice age methane budget, Geophys. Res. Lett., 32, L02704, doi:10.1029/2004g1021004, 2005.

Wang, Z., Chappellaz, J., Park, J. Y., and Mak, J. E.: Large variations in Southern Hemisphere biomass burning during the last 650 years, Science, 330, 1663-1666, doi:10.1126/science.1197257, 2010.

Wang, Z., Chappellaz, J., Martinerie, P., Park, K., Petrenko, V., Witrant, E., Emmons, L. K., Blunier, T., Brenninkmeijer, C. A. M., and Mak, J. E.: The isotopic record of Northern Hemisphere atmospheric carbon monoxide since 1950: implications for the CO budget, Atmos. Chem. Phys., 12, 4365-4377, doi:10.5194/acp-12-4365-2012, 2012.

Zhang, Y., Xie, H., Fichot, C. G., and Chen, G.: Dark production of carbon monoxide (CO) from dissolved organic matter in the St. Lawrence estuarine system: Implication for the global coastal and blue water CO budgets, J. Geophys. Res., 113, C12020, doi:10.1029/2008JC004811, 2008. 